\title{
The Effect of Teaching Using Multimedia Program on Academic Performance of Second Grade Students of Secondary Schools in Empirical Sciences Textbook and Its Comparison with Traditional Method
}

\author{
Negin Barat Dastjerdi $1^{1, *}$ \\ ${ }^{1}$ Educational Technology field, Faculty of Education and Psychology, University of Isfahan, Isfahan, Iran \\ "Corresponding author: Negin Barat Dastjerdi, Educational Technology field, Faculty of Education and Psychology, University of Isfahan, Isfahan, Iran, E-mail: \\ n.dastjerdi@edu.ui.ac.ir
}

Received 2014 June 08; Revised 2015 December 09; Accepted 2015 December 25.

\begin{abstract}
Background: Multimedia programs as a powerful tool to be used to improve the quality of education. This study investigated the effect of education using multimedia programs on academic performance of students.

Methods: This research was semi-experimental and pre-test, post-test type with control group. In the present research, 40 students in second grade in 2013 - 2014 in Isfahan city were selected using multistage cluster sampling and random methods in two groups, such as control and experimental. Pre-test was performed for both experimental and control groups before the experiment. Students in the experimental group were trained for three units of empirical sciences lesson for 3 months using training multimedia program for an academic semester and control group were totally taught using the traditional method. At the end of the teaching period, educational performance test was administered simultaneously to the experimental and control groups. At the last phase, re-test was conducted on the studied groups in order to examine the rate of memorization of the taught contents using multimedia program after 3 months. The data collection tools were teacher made tests that its validity and reliability were confirmed. Both descriptive and inferential statistics (mean, standard deviation, and T-test) were analyzed with statistical package for social sciences (SPSS19) software.

Results: The results showed an increase as compared to the pre-test (18.18) and post-test scores (16.35) of the two groups; the experimental group obtained significantly higher achievement test than the control group. Also, the retention test scores of the students in the experimental group showed significant difference $(\mathrm{P}<0.001)$ than the control group.

Conclusions: Multimedia as a new tool in teaching has new skills for change in education and improve teaching and learning and it can promote with appropriate and correct application the quality of education in educational systems.
\end{abstract}

Keywords: Multimedia, Education Achievement, Education, Science, Students

\section{Background}

Traditional learning approaches have been effectively transformed with emerging modern technologies, including multimedia, meta-media, and remote communications in recent decades (1) and traditional learning concept emphasizes on memory and has led to creative and dynamic learning (2).

The modern educational system assumes quick learning as necessary and it takes help from many facilities and resources to facilitate learning and academic achievement for the students by making students' minds and senses involved in various learning and educational fields. Multimedia are one of these facilities, which diversify teaching process by involvement of students' mind and senses and improve their interest and motive for learning and cause focusing and drawing their attention and care on the given subject and content (3).

Multimedia are some tools that employ various audiovisual senses for information storage and processing as well as communication. Multimedia involve the several senses of the audience at the same time, therefore may lead to increase of internal learning. At the present age, everincreasing dominance of multimedia is witness that may communicate with the learner and with respect to individual differences; they may play an essential role in training facilitation in learners. Learning is one of the most complicated capabilities of human, such that many dimensions of this process are yet unknown and ambiguous and human knowledge fails to justify it. In cognitive learning theory of multimedia, it is assumed that human's information, a processing system comprises two separate channels for visual-imaging and audio and verbal processing 
where there is some limited capacity for processing in any channel and active learning requires execution of a series of coordination in relation to cognitive processing trends during learning (4). Learning is increased in students by means of multimedia and their contribution, benefitting from several senses simultaneously (5).

Likewise, employing multimedia programs in teaching, learning environments is deemed as an appropriate and needed method to discover and access the information sources to prepare learners for the future life and it is considered as one of the main growth, creativity, and change factors in pervasive behavior in learning environment (6). Accordingly, many teaching systems have tried in recent decades to improve learning at minimum period of time using modern technologies (7).

Most of the conducted researches and investigations in this field also signify the useful nature of this tool in creating better learning and savings in time for teacher and learner. For instance, a study about the impact of using multimedia in learning and educational performance is dealt with. In a survey, Kendrasue explored the effect of computerized programs in learning English language lesson and concluded that using software and computerized sources might increase the learning of English language (8). Keppell, Anneta, and Wiebe concluded in their investigations that multimedia-based teaching might contribute to comprehension and retention in students $(9,10)$. In a study, Almekhlafi analyzed the impact of learning language with the aid of computer on achievement and motivation of students in learning English as foreign language (EFL) in United Arab Emirates (UAE). The results showed that there was significant difference among a group who had passed computerized learning and those who had learn using the traditional method and testing group enjoyed further motive for learning English language (11).

Bashiri and Attaran have carried out a survey titled 'utilization from educational aid software for physics lesson at high school third grade and explored its impact in academic achievement. The results showed that the use of computer might significantly affect the improvement of students' learning and increase their interaction with others and strengthens the spirit in doing teamwork (12).

In a study that was conducted by Lakdashti et al under the title of "Impact of teaching simulation software for learning and memorization of students and comparing it with traditional method", they showed that there was significant difference between learning and memorization in teaching using simulation software and traditional training (13). In a study done by Mosa Ramezani titled the effect of teaching by multimedia and lecture on motivation, academic achievement, and self-regulation of remote students. He concluded that teaching by means of mul- timedia might further affect academic achievement and self-regulation than using the traditional teaching method (14). In a research implemented by Saffarian et al, they compared the effect of teaching using the training software for mathematic lesson with training using the traditional method for learning. The results showed that the students who have been trained using educational software had better performance in academic achievement test as compared to students who were trained using traditional learning method (15). A study was conducted by Rastegar Poor and Yadolahi titled the effect of dynamic and static graphic images on learning geometry lesson. The results showed that there was no significant difference between learning method of geometry by means of dynamic and static graphic images (16). In a research that was carried out by Gharibi titled educational multimedia in learning and memorization of mathematical concepts in the first grade trainable intellectual disable students, concluded that the interactional multimedia might activate students and it could be remarkably efficient in learning (17). In this regard, the results from the study by Zakeri showed that the educational performance of students who were trained using educational software was noticeably better in test of academic achievement when compared with the traditional method (18).

Review of this history showed that multimedia present the contents with framework of images, words, writing, movies, and/or sound and the process of message conveyance is done simultaneously; thus, they can cause total cognitive capacity in students to be employed for information processing and since the message is received through several senses, the memorization and learning would be done better to great extent. Multimedia have entered into educational field as one of the modern training tools in recent decades and over shadowed and improved teachinglearning process and thus academic achievement; therefore, they are considered to be noticeable and subject of study. It was characterized by review of research history that most of the studies have explored the effect of multimedia in Mathematics and English language lessons. Thus, the impact of teaching using multimedia programs in empirical sciences lesson has been noticed in recent research and this study is mainly intended to analyze the effect of training using multimedia on educational performance of second-grade students in secondary schools as regards empirical sciences textbook. In order to achieve this objective, the following hypotheses were interpreted.

1) In comparison with the traditional teaching method, using multimedia programs may improve the educational performance of students in training of empirical sciences lesson.

2) In comparison with the traditional teaching tech- 
nique, application of multimedia programs can increase memorization of trained concepts for students in training of empirical sciences lesson.

\section{Methods}

The present research was a semi-experimental and pretest, post-test type with control group. The present study was conducted on 40 female second-grade students from secondary schools in Isfahan city in academic year (2013 - 2014). The participants were selected using multistage clustered sampling technique and divided randomly into two experimental group (20 students) and control group (20 students). Given that the sample size should be at least 15 participants in the semi-experimental researches (19), therefore, the sample size in the present study included two classes in which 20 students were present at any group. The sampling process steps are as follows: one area was selected among five regions of education organization in Isfahan city (Area No. 3) and between schools in the selected areas, a secondary school with two secondgrade classrooms were chosen for the research.

The research inclusion criterion included a member in the given sample group by researcher in the current study (that is, female fourth-grade students from primary school and teachers in this level) while the exclusion criterion was considered as lack of tendency of participants (teachers and students) for cooperation and participation in the study.

Data collection tools were as follows: 1) questions about educational performance in empirical sciences lesson that was prepared by teachers in schools with respect to goals and headlines of the selected lessons. The questions of this test were prepared from the first chapter of empirical sciences book, including three parts titled sciences and their tools, materials of life alphabet, and godgifted resources. Given that this chapter was taught during the first semester of academic year by teachers, it was selected as a sample of total textbook. The exam questions were also designed and selected from the given sections proportional to the related goals by teacher and under supervision of a group of experienced teachers (5 teachers) in empirical sciences lesson. The ethical cases and proper preservation and maintenance of questions were observed before administration of research at all processes of design and execution of test and the test was implemented with the presence of an observer on behalf of the school principal at two pre-test and post-test phases. This test consists of four-choice and explanatory questions with short answers. Questions were scored according to scores from 0 to 20. Similarly, content validity was used to evaluate validity level of test and the prepared questions were at the disposal of four teachers of empirical sciences lesson with more than 10 years experience and they examined the questions with respect to objectives for teaching empirical sciences lesson and proposed some corrective comments in this regard and confirmed the appropriateness of the test questions based on goals of lesson and among a total of 20 designated questions, only 10 questions were chosen for final administration in two pre-test and post-test phases. The existing correlation between scores of empirical sciences lesson test with the scores of variable of students' educational performance showed that this test enjoyed good criterion validity $(r=0.85)$ where it was significant at this level $(\mathrm{P}<0.05)$. Cronbach alpha coefficient was also used to measure test reliability and the given value of coefficient (0.89) shows favorable reliability of test. 2) The multimedia program of empirical sciences lesson was prepared by the research and planning organization. This program was selected for this study, because researcher selected multimedia program of empirical sciences lesson at second grade in secondary school after interview with experts in educational technology office of education organization and visited multimedia programs prepared by this center and with respect to the fact that the produced programs in this center have been verified by experts and scholars in terms of content and professionally. This program consists of all multimedia elements, including text, image, animation, sound, online tests, video clips, simulation lab, and the trend of presentation of subjects is from simple to complex and from objective to abstract following the lesson goals in this program. Similarly, the program possessed interactional aspect and the learners receive the needed feedback after giving answer. Of other facilities of this program, one can refer to the presentation of the contents as video clips and in visual and interactional forms, virtual tours, possibility for the addition of educational elements by teacher and student, and presentation of standard interactional questions and drills in exam section.

The present research was conducted at three phases. Primarily, the quality of working with multimedia program and the given project was trained for teachers in testing group in 2 sessions. This training included working with computer and multimedia program and their various elements by focusing on teaching skills and goals of empirical sciences lesson. With the fact that the first chapter of this book, which includes three units was taught at first semester of academic year, the lesson syllabus of the three units of the first chapter in this book was written by teachers of the testing group using multimedia program and under the supervision of researcher. Also, to ensure the quality of working with multimedia program, a trial teaching session was held in the presence of the researcher. At first step, pre-test of empirical sciences lesson 
was executed from two testing and control groups and students in the testing group were trained for three units of empirical sciences lesson (pp 7 - 68) using training multimedia program for an academic semester (3 months) and the control group was totally taught using the traditional method. It should be noted that the researcher has attended first teaching sessions to ensure proper execution of the project. At the end of the teaching period, educational performance test was administered simultaneously to the two testing and control groups. At the last phase, the re-test was conducted on the studied groups in order to examine the rate of memorization of the taught contents using multimedia program after 3 months. The research results were analyzed statistical package for social sciences (SPSS 19 version) and t-test of independent groups was employed for analysis of difference between the two groups. Full satisfaction of participants in this research was one of the ethical considerations in this study and after giving information about the quality of research execution for participants, the conscious consent form was taken from them to provide it. Furthermore, non-disclosure of names of participants and the scores resulting from employed tests in this study was one of the ethical considerations in this research.

\section{Results}

Two groups have been cohort in terms of gender and individual backgrounds attributes in the present research that was carried out on second-grade female students in secondary schools. The total sample was 40 female students who were 13 years of age. Initially, the descriptive analysis was done in this step to test the hypotheses and ttest was used for two independent groups for this purpose.

The data in Table 1 showed the mean and standard deviation of scores in t-test in pre-test for learning concepts of empirical sciences lesson. The mean score of the control group is 16.35 in pre-test and it is 16.25 in the experimental group and when comparing the mean values in both groups for pre-test shows that there is no difference between the scores of both groups. Likewise, the result of independent t-test (-2.202) and derived Pvalue in the experimental group (0.081) also shows that there is no statistical significant difference among scores between the two control and testing groups at pre-test phase and t-test are under educational status that is close to each other and no significant difference has been observed in terms of pre-test scores among them.

Based on the findings in Table 2, the mean scores of the control group (17.10) and experimental group (18.18) have been calculated, while comparing the means in two groups shows that there is difference in mean values among scores of the two groups at post-test phase. Also, the results of the independent t-test (1.503) and the given $P$ value $(0.000)$ show that there is significant difference among mean scores of pre-test and post-test between the two groups and testing group that has been trained using multimedia programs had better educational performance than the control group. With respect to the comparison between scores of t-test at the pre-test phase (as given in Table 1) and post-test stage, it was identified that there was significant difference between scores in the two pretest and post-test phases and t-test had higher mean score in educational performance test than the control group at post-test phase; so this shows the effect of teaching using the multimedia.

The information in Table 3 showed the mean scores and standard deviation on the pre-test and post-test participants to learn the concepts of science. Statistical comparison between the experimental and control groups in the pre-test showed that there was no difference between the two groups. Also, the comparison of post-test scores showed that there was a difference between the mean scores of the two groups and the means score of the experimental group was higher than the control group, which shows that the impact of multimedia on the experimental group was trained using this method. Also, the significant level of the pre-test shows that no statistically significant difference between the experimental and control groups and the subjects in the study were close to each other and there were no significant differences between the pre-test scores. The mean scores in the post-test showed significant difference between the two groups and the experimental group trained using multimedia programs, came out with better academic performance than the control group.

The findings in Table 4 show that the mean scores of the control group (15.05) and experimental group (17.80) have been computed, while the comparison of the mean values in the two groups shows that there is some difference in the mean values between scores in the memorization test between the two groups. Similarly, the results of independent t-test (3.31) and the given P value (0.001) show that there is a significant difference among the mean value of retention test scores (range test) for which the testing group had been trained using multimedia programs as compared to the control group that was trained using traditional method and teaching using multimedia programs has further affected the memorization in students than using the traditional method. Similarly, with respect to mean scores of t-test at the pre-test stage in the two groups control and testing as shown in Table 1 and also the difference in mean scores of t-test at post-test phase (Table 2), it was characterized that the t-test had better perception of the given subject and acquired higher educa- 
Table 1. Comparison of Mean Scores of Pre-Test in Experimental and Control Groups

\begin{tabular}{l|c|c|c|c|c}
\hline Statistical Parameters Group & Number & Mean & Standard Deviation & T-Value & Significance Level \\
\cline { 1 - 5 } Experimental & 20 & 16.35 & 1.85 & -2.202 & 0.081 \\
\hline Control & 20 & 16.35 & 1.83 & & \\
\hline
\end{tabular}

Table 2. T-Test of Independent Groups to Compare Two Experimental and Control Groups at Post-Test Phase

\begin{tabular}{l|c|c|c|c|c}
\hline Statistical Parameters Group & Number & Mean & Standard Deviation & T-Value & Significance Level \\
\cline { 1 - 5 } Experimental & 20 & 18.18 & 2.32 & 1.503 & $<0.001$ \\
\hline Control & 20 & 17.10 & 1.15 & \\
\hline
\end{tabular}

Table 3. Comparison of Mean Scores of Pre-Test and Post-Test in Experimental and Control Groups

\begin{tabular}{lcccc}
\hline Group & Pre-Test Mean & Pre-Test Standard Deviation & Post-Test Mean & Post-Test Standard Deviation \\
\hline Experimental & 16.35 & 1.85 & 18.18 & 2.32 \\
Control & 16.25 & 1.83 & 17.10 & 1.55 \\
\hline
\end{tabular}

tional performance than pre-test stage after using multimedia programs. Likewise, the trained subjects in the testing group have been more stable and durable than in the control group.

\section{Conclusion}

The present study was conducted in order to compare the effect of teaching using multimedia programs on educational performance in empirical sciences lesson and comparing it with the traditional method. The results of this research showed that the educational performance of students, who were trained using the multimedia programs, were at higher level than students that were taught using the traditional method and this finding complies with the results of the studies done by Mosa Ramezani (14), Safariyan et al (15), and Zakeri (18). Similarly, the results of this investigation showed that there was significant relationship among teaching using multimedia programs in terms of the rate of memorizing trained subjects as compared to the traditional technique and students, who had used multimedia programs for learning concepts of empirical sciences lesson enjoyed higher rates of memorization and learning these concepts than using the traditional method and this finding was aligned with the studies of Keppell (9), Anneta and Wiebe (10), and Lakdashti et al (13). Active learning and contemplative involvement in subjects have transformed learning environment using multimedia programs and contributed to create motive and retention of trainings and stability of textbook materials in memory of the learners. Using several elements, such as image, sound, animation, simulation, graphics, and simultaneous involvement of several senses, the multimedia programs may provide this opportunity for students to be able to receive the contents more accurately and with higher attractiveness (20-22). As mentioned in previous part of this study, despite the fact that many conducted studies show the effectiveness of multimedia programs in teaching, but it should be noted that the rate of achievement of these programs in teaching is highly under the influence of the quality of preparation and presentation and also text subject. Also, the requirement for equipments such as computer with high-speed processing is deemed as one of the constraints for using multimedia programs.

On the other hand, production of multimedia programs requires the consumption of time and cost where the researcher has encountered these constraints in the present study as well. Of course, it is important to note that along with the aforementioned limitations, the leading strong point of this study is to determine the rate of effectiveness of using multimedia programs in rate of learning and retention of the trained subjects. Based on the given results, it is suggested to teachers to use multimedia programs, because of the following reasons:

- Novelty and unique aspects of the technique for the presentation of subjects with training software has attracted learners' interest and attention and caused their active learning and academic achievement.

- It has led to subjective involvement and rising interest and wish in students and eventually better perception of textbook contents and retention of rate of trainings.

Given that the current research was carried out on 
Table 4. The Results of Independent T-Test to Analyze the Effect of Training Using Multimedia Programs on the Rate of Memorization of the Trained Concepts (Range Test)

\begin{tabular}{l|c|c|c|c|c}
\hline Statistical Parameters Group & Number & Mean & Standard Deviation & T-Value & Significance Level \\
\cline { 1 - 5 } Experimental & 20 & 17.80 & 1.38 & 3.31 & 0.001 \\
\hline Control & 20 & 15.05 & 1.62 & \\
\hline
\end{tabular}

the effect of multimedia programs in educational performance of empirical sciences lesson, so it necessitates the implementation of other studies with other subjects and lessons and different educational courses. The results of this study may be helpful for teachers, principals, and planners of education system in identifying the role and effects of various multimedia programs in teaching-learning process.

\section{Acknowledgments}

At the end, researcher deems it necessary to express gratitude to all teachers, who participated in this study.

\section{Footnotes}

Authors' Contribution: We ask authors to describe what each author contributed, and these contributions to the work may be published at the editor's discretion; study concept and design: Fortes, Melchi, and Abeni; analysis and interpretation of data: Fortes, Mastroeni, and Leffondre; drafting of the manuscript: Fortes; critical revision of the manuscript for important intellectual content: Mastroeni, Leffondre, Sampogna, Melchi, Mazzotti, Pasquini, and Abeni; statistical analysis: Fortes and Mastoeni; Yoon Kong Loke developed the original idea and the protocol, abstracted and analyzed data, wrote the manuscript, and is guarantor; Deirdre Price and Sheena Derry contributed to the development of the protocol, abstracted data, and prepared the manuscript.

Conflict of Interest: To prevent the information on potential conflict of interest for authors from being overlooked or misplaced, mention this information in the cover letter. Authors must identify any potential financial conflicts of interest before the review process begins. Declared conflict of interest will not automatically result in rejection of paper but the editors reserve the right to publish any declared conflict of interest alongside accepted. The following would generally be regarded as potential conflicts of interest: 1, Direct financial payment to an author for the research or manuscript production by the sponsor of a product or service evaluated in an article; 2, Ownership of shares by an author in the company sponsoring a product service evaluated in an article (or in a company sponsoring a competing product); 3, Personal consultant for companies or other organizations with a financial interest in the promotion of particular health care products and services.

\section{References}

1. Grisson DR, Anderson T. Electronic learning in 21 century, theoretical and practical foundation (In Persian).. Tehran: Ollom and phonon publication; 2005

2. Jaryani A. Effect of ICT on curriculum development (In Persian) Tehran: Office of Planning and writing vocational school and work publication; 2001.

3. Shoaree Nejad A. Psychological foundations of education(in Persian) Tehran: Institute for Humanities and Cultural Studies publication 1995.

4. Zareezavaraki E, Avaz Zadeh E. Principles of multimedia instructional design (in Persian).J Edu Technol. 2007;2(2):23-5.

5. Razavi SA. .;(): [] . Theoretical foundations of learning by movies and television (in Persian). J Edu Technol. 2007;5(4):23-35.

6. Kafashi HR. Educational software (in Persian). J Edu Technol. 2009;9(6):17-9.

7. Fahimi M. The role of information technology in education (in Persian). Rahyaft. 2001;25(4):218-23.

8. Kendra Sue H. A descriptive analysis of a computer assisted instruction development English program.. J Edu Technol. 2001;62(10):32.

9. Keppell M. Optimizing instructional design-subject matter expert communication in the design \& development of online \& multimedia projects. Commun ACM. 2009.

10. Wiebe E, Annetta L. Influences on visual attention distribution in multimedia instruction. J Educ Multimed. 2008;17(4):259-77.

11. Almekhlafi A. The effect of computer-assisted language learning (call) on united arab emirates efl school students' achievement and attitude. J Inter Learn Res. 2006;17(2):121-42.

12. Bashiri SF, Attaran M. Using software to help secondary school physical education and effect of its in academic achievement and interactive of students in class (in Persian). Except Child. 2007;69(6):84-9.

13. Lakdashti A, Yousofi R, Khatiri K. Impact of simulation software in learning and retention of students and comparative with traditional teaching (in Persian). J Inform Commun Technol Educ. 2011;3(2):21-36.

14. Ramezani SM, Heydari $\mathrm{H}$. The effect of multimedia teaching and lecturing on academic motivation and Self-regulation in distance education students (in Persian).. J Technol Educ. 2011;6(1):45-57.

15. Safariyan S, Fallah V, Mirhosseini SV. Comparing the effect of using educational software and traditional method of learning mathematics (in Persian).J Inform Commun Technol Educ. 2010;3(3):26-34.

16. Rastegar Poor $\mathrm{H}$, Yadolahi M. The effect of dynamic and static graphics on learning geometry (in Persian). J Inform Commun Technol Educ. 2010;1(2):63-76.

17. Gharibi F. The effect of multimedia teaching, learning and retention of mathematical concepts on educable mentally retarded students in fourth grade in Arak city (in Persian). Tehran: Allameh Tabatabee University; 2009. 
18. Zakeri A. Comparing the effects of educational software and traditional education on academic achievement in mathematics first grad school in Tehran (in Persian). Tehran: Tarbeyat Moallem University; 2001.

19. Gal M, Bori V, Gal G. Quantitative and qualitative research methods in science Education and psychology (In Persian). Tehran: SAMT publication; 2004.

20. Chang CY. The impact of different forms of multimedia cai on students' science achievement. Innov Educ Teach Int. 2002;39(4):280-8. doi: 10.1080/13558000210161052.

21. Chen C, Sun Y. Assessing the effects of different multimedia materials on emotions and learning performance for visual and verbal style learners. Computers Educ. 2012;59(4):1273-85. doi: 10.1016/j.compedu.2012.05.006.

22. Koseoglu P, Efendioglu A. Can a multimedia tool help students' learning performance in complex biology subjects?. South African J Educ. 2015;35(4):1-12. doi: 10.15700/saje.v35n4a1169. 